\title{
Measurement of Left Ventricular Ejection Fraction
}

National Cancer Institute

\section{Source}

National Cancer Institute. Measurement of Left Ventricular Ejection Fraction. NCI

Thesaurus. Code C37946.

A measure of how much blood the left ventricle of the heart pumps out with each contraction. With each beat, a normal heart ejects about one-half to two-thirds of the blood in its left chamber. 